\title{
What Do Ecological Paradigms Offer to Conservation?
}

\author{
Som B. Ale $e^{1,2}$ and Henry F. Howe $e^{1,3}$ \\ ${ }^{1}$ Department of Biological Sciences ( $\mathrm{m} / \mathrm{c}$ 066), University of Illinois at Chicago, 845 W. Taylor Street, Chicago, IL 60607, USA \\ ${ }^{2}$ Department of Fisheries, Wildlife and Conservation Biology, University of Minnesota, 200 Hodson Hall, 1980 Folwell Avenue, \\ St. Paul, Minnesota, MN 55108, USA \\ ${ }^{3}$ Department of Zoology, Field Museum of Natural History, 1400 S. Lake Shore Drive, Chicago, IL 60605, USA
}

Correspondence should be addressed to Som B. Ale, sale@umn.edu

Received 8 February 2010; Accepted 12 April 2010

Academic Editor: Bradford A. Hawkins

Copyright ( 2010 S. B. Ale and H. F. Howe. This is an open access article distributed under the Creative Commons Attribution License, which permits unrestricted use, distribution, and reproduction in any medium, provided the original work is properly cited.

\begin{abstract}
Ecological theory provides applications to biodiversity management—but often falls short of expectations. One possibility is that heuristic theories of a young science are too immature. Logistic growth predicts a carrying capacity, but fisheries managed with the Lotka-Volterra paradigm continue to collapse. A second issue is that general predictions may not be useful. The theory of island biogeography predicts species richness but does not predict community composition. A third possibility is that the theory itself may not have much to do with nature, or that empirical parameterization is too difficult to know. The metapopulation paradigm is relevant to conservation, but metapopulations might not be common in nature. For instance, empirical parameterization within the metapopulation paradigm is usually infeasible. A challenge is to determine why ecology fails to match needs of managers sometimes but helps at other. Managers may expect too much of paradigmatic blueprints, while ecologists believe them too much. Those who implement biodiversity conservation plans need simple, pragmatic guidelines based on science. Is this possible? What is possible? An eclectic review of theory and practice demonstrate the power and weaknesses of the ideas that guide conservation and attempt to identify reasons for prevailing disappointment.
\end{abstract}

\section{Introduction}

A paradigm in ecology is a set of concepts, standards, or ideas that guide the advancement of scientific knowledge at any of a variety of spatial and temporal scales $[1,2]$. Such conceptual frameworks as the population regulation, island biogeography, and metapopulation dynamics are paradigmatic in the sense that they are socially constrained ideas about how organisms interact with nature, major aspects of which are socially constrained standards for determining the questions worth asking and the answers worth accepting. The hope is that paradigm refinement and extension allow theoretical and practical ecologists to construct and apply "predictive" models that both explain and guide the management of nature.

The stakes in finding a rational basis for management of nature are high. No part of the earth is unaffected by human impact driving species to extinction at unprecedented rates [3-5], despite investment of billions of dollars worldwide to stem biodiversity loss [6]. Ineffective management of living resources may have immediate costs, whether the resource is a $\$ 230$ million commercial salmon fishery in Alaska or a \$2 million annual economic value of deer hunting in a single New Brunswick forest [7]. Summed over relevant industries, the calculable costs of failing to manage nature are immense. Far broader impacts, falling loosely under the rubric "ecosystem services," might occur with poor management with costs that are far more difficult to calculate even with known variables. A risk is that costs of failure including such unknowns dwarf "immense" that can now be calculated.

One would think that investment of large sums of money in accordance with the best available science would stem the loss of the most obvious species of public concern, but the hope has not been realized. Humans depend on commercial fisheries for food, yet fishery industries, one after another, have collapsed, and some, like the Pacific salmon industry, that have survived under exploitation, have done so for 
unknown reasons (e.g., [8]). Attempts to ensure a cultural legacy of nature, as we know it, fare no better. In recent decades, for example, a focus on taxa shows that 173 species of mammals have lost $>50 \%$ of their historic range areas [9]. Slightly more than 1 out of every 5 mammalian species $(1,141$ of 5,488 described species) is currently threatened with extinction [10]. The global demise of mammals can be viewed as one of abject failures in conservation. Many species, if they persist in the wild at all, do so as mere remnants of their former abundance and distribution. More far-reaching, destruction, fragmentation, and disruption of entire ecosystems races forward [11], raising the prospect that many species will be lost before they are even identified, much less known in any depth. Despite unprecedented financial investment by governments and the private sector [12], conservation does not appear to meet expectation.

Could faithful application of basic principles of ecology stem this loss? Or are the principles failing because they cannot be applied competently? An easy but insufficient answer is that the principles may be adequate, but their application to conservation is flawed because of unintentional social or political interference at times hampering resource exploitation on sustainable basis. While it is hard to dispute that the best ecological model in the world may not halt giant international factory ship fleets from destroying fisheries, it may be that social control reaches a deeper level in the structure of science itself. Ecological paradigms tend to evolve themselves and are applied in ways that perhaps limit their utility. If this is true, what should resource managers expect of ecology as a science? How can academics change ecology as a science to make it more operational as a guide to management of nature? We examine how some central ecological ideas elude resource managers or succeed in conservation and explore ways in which the social component of ecological paradigm evolution can do a better job.

\section{Where Paradigms Succeed and Fail?}

2.1. Sustainable Yield. A central paradigm in the management of exploitable resources is sustainable yield [13]. The key assumption is that wild populations produce "excess" individuals which then can be "harvested" without diminishing the capacity of the population to maintain a more or less steady state, much like harvesting a maize crop with sufficient seed protected for future use. The ecological basis for this idea is logistic thinking (e.g., [14]). Populations reach a carrying capacity $(K)$, representing a number of individuals that fully use the available resources, above which population growth slows and starvation or disease take their toll. If a population has age structure, like a fish, grouse, or pine tree, births exceed deaths (the difference being the intrinsic rate of increase, $r$ ) and offspring cohorts overshoot carrying capacity. These are the "excess" individuals to be "harvested." What managers must do is maintain populations at levels at or below $K$ where they produce abundant excess individuals, without depressing the population beyond recovery. An issue is whether harvest is set at some level below maximum sustainable yield as indicated by a specific projection of excess or some sustainable level below that projected level to add resilience to use (e.g., [15]). Managers must avoid exploitation to severe as to "eat the seed corn" or precipitate accidents that have the same effect.

The virtually universal concept of sustainable yield has mixed results. Its success is evident in management of game animals in North America where provincial and state governments in Canada and the United States successfully regulate small and large game populations and sport fisheries. Basic demographic estimators set limits for harvest of animals as diverse as bobwhite quail [16] and black bear [17]. For heavily hunted species, manipulation of the breeding system and effective breeding population $\left(N_{e}\right)$, such as occurs in male-only hunts for deer (e.g., [18]), allow sustainable harvest indefinitely. Targeted protection and active management can even bring some game species, like the Masked Quail in the south-western United States, back from the brink of extinction [19]. On a larger scale, wild turkeys were hunted to 30,000 birds across the entire United States by 1900 but through active management and reintroduction now approach 7 million birds, with active hunting seasons throughout the country (see [20]). Not only have sport game animals in North American avoided extinction under management for sustainable "harvest," but most have prospered.

Commercial fisheries are managed on the same general assumption of a sustainable harvest, but with much less success. The decline in coastal fisheries began during the colonial period in North America, with the largest size classes of many species disappearing by the time biologists began keeping track in the mid-20th Century, just as industrial fisheries took hold [21]. The absence of management may have contributed to drastic declines of many coastal fisheries [22], as did confounding pollution and other forms of habitat destruction.

On a global scale, however, fisheries are subjects of sophisticated management plans, international treaties, and close scrutiny in the last half of the last century to the present, yet still fall short [23]. Twenty-four percent of 1519 fish stocks across numerous species collapsed between 1950 and 2000 [24]. Of these, 33\% of the stocks showed a steady regular decline (smooth collapse), $45 \%$ fell after ups and downs (erratic collapse), and $21 \%$ appeared to be healthy, and then disappeared abruptly (plateau collapse). Smooth collapses suggest steady overexploitation, sometimes confounded by increasing environmental stress from pollution. Erratic collapses might be expected in species that fluctuate greatly in numbers from the dynamics of age structure, often confounded by external events, such as El Niño changes in water temperature that affect food resources. In such examples, harvest levels based on steady-state assumptions are bound to fail if substantial fishing pressure is applied to populations that for one reason or another are in decline or free fall at the time. Plateau collapses of sardines and herrings take place when cryptic increases in harvest efficiency occur, such as increased capture efficiencies or navigation improvements that allow concentrations of fish to be found more easily than before (i.e., regulatory definitions of fishing 
intensity become obsolete). Plateau collapses also occur when reduced populations show "depensatory" inability to recover, amounting to negative Allee effects manifesting in small populations. A result of sequential depletion of traditional fishing stocks is sequential exploitation of previously ignored species at lower depths, what Morato and colleagues [25] term "fishing down the deep", which is bound to reduce the complexity of marine food webs, thereby making ecosystems more vulnerable to damage [26].

Why do principles applied to sport game succeed, but fail when applied to commercial fisheries? The answers are both socio-economic and ecological. The 1992 disaster of the Canadian Grand Banks' Atlantic cod (Gadus morhua) shows just how badly fisheries policies can go wrong, when scientists' advice of setting lower catch quotas using less harmful fishes gear is ignored [22]. Capital-intensive industrialized fishing fleets are politically and logistically difficult to modulate [8]. Lotka-Volterra theory might work in fisheries if instant feedback of demographic trends allowed effective regulation of the intensity of effort. It does not occur. Constant pressure on inherently stable populations often results in slow decline to collapse, and constant pressure on erratic populations leads to erratic collapse. Constant improvement in fishing technique, magnified across a large scale of effort in an industrialized fishing industry, contributes to all three patterns of collapse.

Can we learn anything from successful game management? A key difference is that sport hunting in North America is a far less intense risk to game populations than commercial fishing is to fish stocks. Strictly enforced hunting seasons, bag limits, regulations constraining equipment (e.g., cartridge limits for shotguns, bans on fully automatic rifles), and the fact that most sport hunters do not hunt from necessity ensure that a human predator is as inherently inefficient as industrial fishing fleets are inherently efficient. Relentless commercial hunting with unsophisticated firearms in tropical forests, however, is far more destructive to game populations [27] and to the forests in which they play a role [28], with the key differences from sport hunting being motivation and constant hunting pressure. Demands of the markets make application of sustainable yield theory in conflict with motivations of bush-meat hunters and fishing fleets far more than with people who hunt and fish for relaxation.

Other structural differences between sport and commercial harvest may be important. Hunting seasons in the temperate zone only occupy a few days or weeks of the year, leaving a long refuge in time. Furthermore, many hunted birds or mammals also have refuges in space (e.g., parks, proximity to human habitation, and inaccessible habitats). Even the protozoa that introduced logistic thinking survive intense predation in a vial if they have refuges [14]. Enforced regulations that ensure inefficiency distinguish sport hunting from commercial fishing or hunting, where there is a premium on increasing efficiency and refuges either do not exist or are insufficient. In this sense the suggestion by Roughgarden and Smith [29] that harvest targets be lowered to leave more leeway for fluctuations and therefore more likelihood that "seed stocks" will be preserved, seeks to make multibillion dollar commercial fishing industry more like sport hunting or sport fishing.

2.2. Island Biogeography. One of the most influential ecological paradigms in conservation is the theory of island biogeography $[30,31]$. The theory predicts that the log of species number increases with the log of habitat area due to an equilibrium of immigration and extinction in each habitat island, where an island is a habitat fragment separated from others by unsuitable matrix. A corollary is that species number declines when area decreases as large habitat patches are carved up into small ones. The theory is for predicting the number of species that might be expected in a given habitat unit, for planning refuge areas, and for estimating the number of species likely to be lost if a large patch is fragmented into small patches.

The theory of island biogeography has contributed to important insights about the efficacy of refuge design (reviewed by Doak and Mills [32]). Large refuges hold important species that small ones do not, heterogeneous refuges hold more than homogeneous ones, communities on islands surrounded by truly alien habitat (e.g., water) have different dynamics than communities surrounded by more amenable matrices of vegetated land, and the slopes of species area relationships reflect taxon vagility. The theory has also catalyzed debate about conservation values. For instance, numerous small refuges hold as many or more species than a single large refuge of the same aggregate area [33], but the identity of species differs [34]. Large patches hold habitat specialists that small patches do not (e.g., [35]). For instance in tropical forests, $80 \%$ of tree species in continuous forests are late-successional and often quite rare, and $20 \%$ are pioneer or early successional species that are often quite common in disturbed areas [36]. A constellation of small fragments might successfully encourage a fair number of the $20 \%$ secondary forest species but underrepresent the majority $80 \%$. In general, the theory of island biogeography has been useful when the focus was in species number rather than species composition.

Limitations of unadorned island biogeographic theory are due to weak predictability. The total number of species likely to persist in island habitats of different size often has broad confidence intervals $[37,38]$, and unexpected anomalies in the shape of the $(\log )$ species number versus $(\log )$ area relationship for some communities add to statistical imprecision (e.g., [39]). More fundamental, the theory itself predicts vulnerability to extinction solely from increasing proportion of species with very small population sizes as island size decreases [40]. It is silent on which species are vulnerable for reasons other than small population size. For that, one must know more about species involved, such as the existence of obligate mutualisms that link fates of species (e.g., [41]), and developmental stability of morphological characters [42]. In the first case, chance loss of avian dispersal agents reduced dispersal and establishment of seedlings of an endemic tree (Leptonychia usambarensis) in Tanzania, a kind of linked occurrence which may be common in nature, especially in tropical regions. In the 
second case, species mobility and developmental stability (low fluctuating asymmetry) of morphological characters were positively associated with persistence of bird species in forest fragments in Kenya. Whereas the general theory is operational in a limited sense of predicting total species richness, chance loss or persistence of key interacting species reduces predictability, while insights about fluctuating asymmetry imply different kinds of outcomes for different species. Implementing Lens' et al. [42] perspective, for instance, bird species with low mobility and high fluctuating asymmetry would need larger reserves than those with higher mobility and greater developmental stability.

Application of the theory of island biogeography to the worldwide phenomenon of habitat fragmentation is sometimes over optimistic (e.g., [43]). Not all matrices are equal from the perspective of particular taxa (e.g., [44]). Water is a more alien matrix than agricultural land, and water is more alien for arboreal or terrestrial mammals than for bats. Forest fragments separated by matrices of vegetated land will be islands for some species, but to a lesser degree or not at all for others. Attempts to apply the theory without such considerations may overestimate island effects and underestimate the nonrandom factors that shape communities in remnants.

2.3. Metapopulations. Metapopulations are populations of populations $[45,46]$. Much as individuals of populations are born, grow, die, and are replaced by new individuals, populations of a metapopulation establish, grow, die, and sooner or later re-establish in the same place or colonize new sites. Subpopulations of a species, separated from others by unsuitable habitat, come and go. If more populations decline and disappear than grow and establish, a species declines. If more populations grow than decline, a species population grows. If more establish in new sites than are lost, the species spreads.

The theory has obvious relevance to conservation and restoration of species, as well as to habitat fragmentation $[46,47]$. If metapopulations exist in nature and behave as models predict, this conceptual framework might integrate population and island biogeographic perspectives in a paradigm that has much to offer conservation and ecological restoration of populations. If most species behave as metapopulations, communities of metapopulations, "metacommunities," may be modelled accordingly.

Some species do behave as metapopulations. The Florida scrub jay Aphelocoma coerulescens is an excellent case in point [48]. Subpopulations range in size from less than 10 to one of 1500 individuals, so this is far from the classic Levins [45] model. But exhaustive study shows that dispersal is consistent, populations disappear and recolonize, and recolonization is more likely close to than far from occupied patches of suitable habitat. In general, the special conditions exist for metapopulation analysis. If one is interested in scrub jay management, the metapopulation paradigm provides important tools.

Despite its plausibility and clear relevance to such cases as the scrub jay, the concept of metapopulations has not proven as operational as hoped [32]. First, interchange among subpopulations often cannot be assumed or may occur in one direction. Larger populations or clusters of populations shed migrants as "sources," while others are small or in marginal habitats and absorb migrants as "sinks" (see a general review in Vandermeer and Goldberg [49, page $167 \mathrm{ff}]$. The conservation question then becomes predicting persistence of only one or a few source subpopulations, which is not a metapopulation concept.

Examples show the complications of use of the metapopulation paradigm for species of conservation interest. Inequality of parameters in different subpopulations requires that modelling persistence of a species relies on site-specific rates of immigration, reproduction, growth, and death. In the western United States the spotted owl Strix occidentalis is a threatened bird of old growth conifer forests, now distributed in forest patches left by clear-cut logging [50]. To simulate persistence of this species in a region, forest by forest estimates of habitat suitability, extinction, migration, and further dispersal must be modelled. For instance, molecular markers do not indicate much or any dispersal of spotted owls among forest patches, suggesting that the species, despite widely scattered groups of individuals and the possibility of dispersal by flight, does not behave as a collection of metapopulations [51]. In California, the total spotted owl prognosis apparently reflects the growth or contraction of owl numbers over a large area in the San Bernadino Mountains, with little influence of more marginal groups [51].

It is not clear that metapopulations are common $[32,34]$. Exhaustive studies of other species show, much as in the spotted owl, that the violations of assumptions of metapopulation dynamics may be more common. Much like the owl example, Harrison [52] argues that the butterfly Euphydryas editha bayensis has a large core population, and many small satellites that superficially but erroneously appear to be metapopulation units, in which the satellite dynamics are determined by dispersal from the core. These examples are more like MacArthur and Wilson's [30] colonization from a source than a paradigmatic metapopulation colonization and extinction dynamics. A serious question then becomes, how much time and effort should be spent on much less charismatic (owl) or tractable (butterfly) species on the likely result that metapopulation dynamics are insufficient for conservation purposes? Perhaps a population viability analysis over much wider areas than previously attempted will estimate persistence of spotted owl and Euphydryas populations in something like a metapopulation analysis, at great cost. Perhaps, as likely, no family of models will do the job well or will be worth the resources required to provide the key empirical validation.

\section{Unrealistic Expectations}

The examples discussed here represent a range of applications of ecological theory to ecological management. Each paradigm offers something important to conservation, and each falls short of expectations. Beyond political and 
economic pressures that tend to compromise assumptions of ecological theory, what common threads can be discerned for these and perhaps many other possible examples on the use of ecological paradigms in practice? Are managers, and often ecologists themselves, asking too much of their theory?

3.1. Numbers. A basic difficulty with ecology is rooted in what, for lack of a better term, may be called statistical mechanics. The behaviour of a single particle is less predictable than the average of several and much less predictable than the average of millions or billions of atoms. In Newtonian mechanics, a falling iron cannonball with a mass of $10 \mathrm{~kg}$, containing billions of iron atoms, is more predictable than the behaviour of an iron atom or 20 iron atoms (e.g., [53]). A consequence is that the accumulated mass of the large body overcomes effects of chance interactions with other atoms or molecules that might easily change the behaviour of small particles but not large ones. A civilization based on mechanical engineering, architecture, and related fields would be in dire straights if the properties of systems used in creating dams, bridges, automobiles, and rockets were deduced from the behaviour of 10-20 independent or clumped atoms or molecules, rather than the accumulated or average effects of thousands, millions, billions, or trillions of such units.

The ecology of many systems is the ecology of very small numbers. In a given community, some species are common, most are uncommon or rare [54]. Many species are so rare that they cannot be studied in numbers, anywhere. The extreme may be in hyper-diverse rainforests of the western Amazon, where most of a thousand or so tree species in a given area occur in densities of less than one per hectare and many in densities of less than one per 10 hectares [55]. A small minority of trees, termed oligarchs, are common across vast stretches of terra firma forest. Oligarch species may be common enough to model or test sustainable yield, island biogeography, or metapopulation dynamics. But the vast majority of "inherently rare" trees simply cannot be sampled with much statistical predictability [56]. An example of the conundrum of inherent rarity is found in a study of one of us (S. B. Ale): effects of snow leopards Uncia uncia on Himalayan tahr Hemitragus jemlahicus on Mount Everest [57]. In a given locale, one or several leopards occur. The effects of these few individual cats on their prey may be idiosyncratic, but they represent the total universe of leopard and tahr interactions in a given valley. Close study offers a comprehensive understanding of cat and prey interactions and their behaviours in valleys with "simple" predator-prey system, but to generalize this to all of Asia has parallels with a chemist trying to follow behaviour of three or four $\mathrm{CO}_{2}$ molecules and $20 \mathrm{H}_{2} \mathrm{O}$ molecules they bump into and generalize to the atmosphere. Patterns would exist, but predictions could not be precise.

The difference in scales of ecological researches and management practices in which findings of such researches are attempted to apply (e.g., [58]) further exacerbates the problems associated with small numbers and predictability.
The hardcore ecological tradition, for example, a preoccupation with experiments, usually dictates that ecological investigations be conducted at relatively fine scales of space and time, but it is not clear how these findings should be extrapolated to the broader scales on which management is usually practiced [59]. Extrapolations from individual traits to populations, community interactions, ecosystems, and landscapes are wrought with escalating errors as every higher scale contributes to a new environment, more history, more adaptations, and more interactions. This becomes increasingly complicated as species rapidly evolve in response to selective-harvesting [60] and with cascading effects as reported by Frank et al. [61] who, for instance, found that the removal of cod by over-fishing led to effects that extended across five trophic levels exceedingly slowing the recovery of cod in a North Atlantic fishery.

3.2. Contingencies. Small numbers have ramifications. Ecological communities of a thousand species have roughly $1000^{1000}$ possible direct pairwise interactions with each other and a virtually infinite number of possible multi-way direct and indirect interactions with each other and abiotic factors. Most potential interactions never occur, but some conditions force more consistent families of outcomes. With just the sheer number of possibilities, the potential for a pervasive influence of contingent effects is clear [62]. The smaller the number of individuals of a species or communities in which a particular abiotic, animal, plant, or anthropogenic effect occurs, the more likely chance or historical contingencies will produce idiosyncratic outcomes. Contingencies emphasized by Lawton [62] include those due to the particular species that are common or rare and their direct and indirect interactions with others. Subsumed under such effects are attributes of each population within a species, including size, local diet choices, local demographies, local behavioural patterns forced by predators, prey, or competitors, and local dispersal properties, as well as local responses to external abiotic factors and regional species distributions. Ecological communities are far from random assemblages of organisms in any given set of abiotic constraints, but Lawton [62] is correct in calling attention to the fundamental role of contingency in determining the distribution, abundance, and behaviour of species.

3.3. Paradigms, Numbers, and Contingencies. The unacknowledged elephant in the room in a discussion of application of ecological paradigms to conservation is that much applied theory does not address contingencies, which become increasingly important as community diversity increases, population density declines, and external and somewhat unpredictable forces like climatic events become important. Most extant fishery models are deterministic, but the world is not. Poor predictions and unexplainable natural stock fluctuations mostly arise from the result of a variable environment so called unpredictable "environmental noise" $[63,64]$, the fact well known to the early twentieth century scientists (e.g., [65]), but few models have attempted explicitly to incorporate environmental factors because they 
introduce complexity (higher number of parameters and hence higher statistical error) into models, thereby decreasing model-precision (sensu, [66]). With only one exception, all of the 58 models [e.g., stock-recruit-analysis, surplus production models, general additive models, and individualbased models], reviewed by Keyl and Wolff [67], for instance, revealed an important influence of environmental and climatic variability on target species and emphasized the importance of the inclusion of such extrinsic factors for prediction.

Apparently, theory seems to apply well to selected examples where animals or plants have been studied in exhaustive detail or are common and their demographies, dispersal, and interactions are predictable in relatively predictable environments, but much less well where numbers are low and contingent effects overwhelming.

Success and failure in the best understood and most economically important examples discussed here, sustainable use of living resources, appear to hinge on the importance of and managing contingencies (see [62]). With commercial fisheries, small numbers are not the issue. The definitive story about decline of fish stocks worldwide concerns $>1500$ managed units [68]. In the case of maximum sustainable yield of commercial fish stocks, the theory assumes that human harvest is the prime driver of the system and that harvest intensity can be regulated. Repeatedly, anthropogenic contingencies in the form of increases in encounter rate and harvest efficiency skirt regulatory measures, increasing harvest intensity leading to overexploitation and then collapse. Ecological contingencies that introduce other drivers often are not included in the models, such as disappearance of food supplies due to unanticipated competition from competing fish species, changes in water temperature from El Niño effects, pollution, and other factors. The end result is that simplistic models that do not accommodate a variety of contingent drivers set the harvest level too high; fishing intensities that might be sustainable if nothing else influenced the fish stocks join other forces driving population levels into negative numbers. In sport fisheries and sport hunting, where harvest levels are set much lower, refuges in time and space exist, and market forces are less relentless, the theory appears to work.

Although theories of island biogeography and metapopulations have played an immense role in reserve designs and biodiversity conservation, in general these theories are especially poor tools for predicting and managing populations that are small or declining in size [69]. The theory of island biogeography is best used to predict and manage overall species richness in habitat islands of different size. Island biogeography and metapopulation theory alike are not especially useful in predicting changes in particular species populations unless more is known than usually can be known about natural history, dispersal, and life history of most plants and animals. Complications of the theory mentioned in the previous section are exacerbated by sampling errors and statistical challenges for most species, in most places. If most communities are characterized by a preponderance of scarce or rare species [54], and the proportion of such species increases with decreasing area (e.g., $[40,70])$, predictions for the majority of species in a community are subject to large sampling errors. Immigration and extinction may be measurable for the few species in a community that are common, but these are not the ones likely to be at risk of extinction in small habitat fragments unless other factors, like loss of a pollinator or dispersal agent or dramatic deterioration of habitat quality, alter the conditions under which even common species may persist.

Sampling challenges are particularly stark in highly diverse tropical forests, where almost all species are infrequent or rare. One can document massive changes in community composition with forest fragmentation (e.g., [71]), but particulars of life history that would help predict exactly what would change, according to metapopulation theory, for instance, is unlikely. For most species in such a forest landscape, even measurement of immigration and extinction, much less prediction of either, are challenges. Imagine a terra firma or floodplain or floodplain forest of the western Amazon with approximately 1000 tree species, mentioned above (e.g., [55]). Thirty to 50 species might be common and widespread "oligarchs" that can be studied in forests and fragments over a wide area, and perhaps 150 to 300 (this number is unknown) uncommon and rare species might have clear habitat specializations that theoretically could be measured and predicted. Existence of habitat specializations might in theory help predict which species would likely disappear from habitat islands or persist despite small numbers. Even in such a hypothetical case, 650 to 800 tree species would be present in such low numbers (1 to 0.01 per ha) that calculation of demographic and natural history attributes would be infeasible or at least subject to large idiosyncratic errors. Some small or large fraction might behave like metapopulations, for instance, but who could ever know?

\section{What Can Managers Expect?}

Use of ecological theory for management of nature needs to follow different rules than use of physical theory to build skyscrapers or rockets. Whereas an engineer has a firm concept of stresses in constructing a structure of steel girders or thrust required to carry a rocket payload, an ecologist has nothing comparable in concepts of sustainable yield, island biogeography, or metapopulation dynamics. In such cases, the theory can guide insight, but the insight must be tempered by local understanding of how well the organisms in question fit assumptions of relevant models. A manager must also realize that even if a population could in theory be managed for sustainable yield or maintained in habitat fragments of different size, populations might usually be so small that firm estimates and therefore predictions of persistence, extinction, or colonization are infeasible. If a Himalayan valley hosts three snow leopards, a manager of the cats and their prey may benefit from understanding that the local population may disappear and be replaced by other individuals or that the cats may simply trade individuals with other valleys. The capacity to actually estimate turnover on a quantitative basis is quite likely out of reach. 
We assert that the quest for developing models that are based on larger, rigorous conceptual framework and that can be tested with appropriately sophisticated methodology should be pursued in ecology. We may profit, however, by acknowledging the shortcomings of ecological predictions, and frankly admitting when prediction is inappropriate because theories are insufficient or not appropriate for the targeted conservation practices (e.g., [72]). Development of predictive capabilities may take time but, as latest fishery science indicates, we are rapidly advancing toward our destinations. For reasons inherent in the field and the nature of nature, resource managers should avoid the pretense of predicting precise population changes as a function of harvest, isolation, or metapopulation turnover. The concept of building resilience into policy to accommodate contingency, error, and chance is an operational approach to using theory for guidance rather than certainty. So, for instance, a general prediction that abundance of edible fish will change the fortunes of whatever game animals are common as indigenous people deplete in the Amazon may be warranted [73], but a pretense of predicting what each game or fish population will be given exploitation of it by indigenous people is not. Regarding reserve size, a prediction of persistence of animals and plants as a function of size of habitat patches may work well in uninhabited areas, but proximity of human settlements may overshadow it in many places [74]. Contingencies that are not present in armchair models affect both examples.

The gist is not that ecological paradigms are failing, but that expectations of ecology as a science are not realistic in the real world in the same way that physics informs engineering or molecular biology informs medicine. Theory premised on predictions from large numbers is not much used in local situations where numbers of most organisms are low and where contingent effects may be overriding.

\section{Acknowledgments}

The authors are grateful to L. Borghesio, J. Brown, N. Cordeiro, J. Ison, A. Kramer, G. Nunez-Iturri, A. Sullivan, and C. Whelan for insightful comments on the paper. They thank the Snow Leopard Conservancy, Felidae Conservation Fund (Z. McDonald), Rufford Small Grants, International Snow Leopard Trust, World Wildlife Fund and Wildlife Conservation Society (SBA), and National Science Foundation (DEB 0129081, 0516259 to HFH) for support of research that contributed to their perspective.

\section{References}

[1] M. H. Graham and P. K. Dayton, "On the evolution of ecological ideas: paradigms and scientific progress," Ecology, vol. 83, no. 6, pp. 1481-1489, 2002.

[2] T. S. Kuhn, The Structure of Scientific Revolutions, University of Chicago Press, Chicago, Ill, USA, 2nd edition, 1970.

[3] F. D. M. Smith, R. M. May, R. Pellew, T. H. Johnson, and K. R. Walter, "How much do we know about the current extinction rate?" Trends in Ecology and Evolution, vol. 8, no. 10, pp. 375378, 1993.
[4] S. L. Pimm and J. H. Lawton, "Planning for biodiversity," Science, vol. 279, no. 5359, pp. 2068-2069, 1998.

[5] M. J. Groom, G. K. Meffe, and C. R. Carroll, Principles of Conservation Biology, Sinauer Associates, Sunderland, UK, 3rd edition, 2006.

[6] A. James, K. J. Gaston, and A. Balmford, "Can we afford to conserve biodiversity?” BioScience, vol. 51, no. 1, pp. 43-52, 2001.

[7] H. MacGregor, The economic value of deer hunting and its distribution in the Fundy Model Forest- 1994, M.S. thesis, University of New Brunswick, New Brunswick, Canada, 1998.

[8] D. Ludwig, R. Hilborn, and C. Walters, "Uncertainty, resource exploitation, and conservation: lessons from history," Science, vol. 260 , no. 5104 , pp. 17-36, 1993.

[9] G. Ceballos and P. R. Ehrlich, "Mammal population losses and the extinction crisis," Science, vol. 296, no. 5569, pp. 904-907, 2002.

[10] IUCN, "Red list summary statistics,” October 2008, http://cmsdata.iucn.org/downloads/2008rl_stats_tables_all.xls.

[11] W. F. Laurance and C. A. Peres, Emerging Threats to Tropical Forests, University of Chicago Press, Chicago, Ill, USA, 2006.

[12] M. Shellenberger and T. Nordhaus, "Death of environmentalism: global warming politics in a post-environmental world," Grist Magazine, January 2005.

[13] R. Hilborn, C. J. Walters, and D. Ludwig, "Sustainable exploitatin of renewable resources," Annual Review of Ecology and Systematics, vol. 26, pp. 45-67, 1995.

[14] G. F. Gause, The Struggle for Existence, Williams \& Wilkins, Baltimore, Md, USA, 1934.

[15] G. D. Peterson, "Ecological management: control, uncertainty, and understanding," in Ecological Paradigms Lost, K. Cuddington and B. Beisner, Eds., pp. 371-396, Elsevier, New York, NY, USA, 2005.

[16] F. S. Guthery, A. K. Crews, J. J. Lusk, R. N. Chapman, and M. Sams, "Effects of bag limits on bobwhite hunters and harvest," Journal of Wildlife Management, vol. 68, no. 4, pp. 1095-1103, 2004.

[17] D. R. Diefenbach, J. L. Laake, and G. L. Alt, "Spatio-temporal and demographic variation in the harvest of black bears: implications for population estimation," Journal of Wildlife Management, vol. 68, no. 4, pp. 947-959, 2004.

[18] B. G. Giles and C. S. Findlay, "Effectiveness of a selective harvest system in regulating deer populations in Ontario," Journal of Wildlife Management, vol. 68, no. 2, pp. 266-277, 2004.

[19] F. Hernández, W. P. Kuvlesky Jr., R. W. DeYoung, L. A. Brennan, and S. A. Gall, "Recovery of rare species: case study of the masked bobwhite," Journal of Wildlife Management, vol. 70, no. 3, pp. 617-631, 2006.

[20] D. G. Dickson, The Wild Turkey: Biology and Management, Stackpole Press, Mechanicsburg, PA, USA, 1992.

[21] J. B. C. Jackson, M. X. Kirby, W. H. Berger, et al., "Historical overfishing and the recent collapse of coastal ecosystems," Science, vol. 293, no. 5530, pp. 629-637, 2001.

[22] Q. Schiermeier, "Fisheries science: how many more fish in the sea?" Nature, vol. 419, no. 6908, pp. 662-665, 2002.

[23] D. Pauly, R. Watson, and J. Alder, "Global trends in world fisheries: impacts on marine ecosystems and food security," Philosophical Transactions of the Royal Society of London. Serirs $B$, vol. 360, no. 1453, pp. 5-12, 2005.

[24] C. Mullon, P. Fréon, and P. Cury, "The dynamics of collapse in world fisheries," Fish and Fisheries, vol. 6, no. 2, pp. 111-120, 2005. 
[25] T. Morato, R. Watson, T. J. Pitcher, and D. Pauly, "Fishing down the deep," Fish and Fisheries, vol. 7, no. 1, pp. 24-34, 2006.

[26] D. Pauly, V. Christensen, S. Guénette, et al., "Towards sustainability in world fisheries," Nature, vol. 418, no. 6898, pp. 689-695, 2002.

[27] C. A. Peres and E. Palacios, "Basin-wide effects of game harvest on vertebrate population densities in Amazonian forests: implications for animal-mediated seed dispersal," Biotropica, vol. 39, no. 3, pp. 304-315, 2007.

[28] G. Nuñez-Iturri and H. F. Howe, "Bushmeat and the fate of trees with seeds dispersed by large primates in a lowland rain forest in western Amazonia," Biotropica, vol. 39, no. 3, pp. 348 354, 2007.

[29] J. Roughgarden and F. Smith, "Why fisheries collapse and what to do about it," Proceedings of the National Academy of Sciences of the United States of America, vol. 93, no. 10, pp. 5078-5083, 1996.

[30] R. H. MacArthur and E. O. Wilson, The Theory of Island Biogeography, Princeton University Press, Princeton, NJ, USA, 1967.

[31] D. Simberloff, "The contribution of population and community biology to conservation science," Annual Review of Ecology and Systematics, vol. 19, pp. 473-511, 1988.

[32] D. F. Doak and L. S. Mills, "A useful role for theory in conservation," Ecology, vol. 75, no. 3, pp. 615-626, 1994.

[33] D. Simberloff and L. G. Abele, "Refuge design and island biogeographic theory: effects of fragmentation," American Naturalist, vol. 120, no. 1, pp. 41-50, 1982.

[34] B. Taylor, "Investigating species incidence over habitat fragments of different areas-a look at error estimation," Biological Journal of the Linnean Society, vol. 42, no. 1-2, pp. 177-191, 1991.

[35] L. Hansson, "Dispersal and connectivity in metapopulations," Biological Journal of the Linnean Society, vol. 42, no. 1-2, pp. 89-103, 1991.

[36] B. Finegan, "Pattern and process in neotropical secondary rain forests: the first 100 years of succession," Trends in Ecology and Evolution, vol. 11, no. 3, pp. 119-124, 1996.

[37] E. F. Connor and E. D. McCoy, "The statistics and biology of the species-area relationship," American Naturalist, vol. 113, no. 6, pp. 791-833, 1979.

[38] W. J. Boecklen and N. J. Gotelli, "Island biogeographic theory and conservation practice: species-area or speciousarea relationships?" Biological Conservation, vol. 29, no. 1, pp. 63-80, 1984.

[39] J. B. Plotkin, M. D. Potts, D. W. Yu, et al., "Predicting species diversity in tropical forests," Proceedings of the National Academy of Sciences of the United States of America, vol. 97, no. 20, pp. 10850-10854, 2001.

[40] R. H. MacArthur, Geographical Ecology, Princeton University Press, Princeton, NJ, USA, 1972.

[41] N. J. Cordeiro and H. F. Howe, "Forest fragmentation severs mutualism between seed dispersers and an endemic African tree," Proceedings of the National Academy of Sciences of the United States of America, vol. 100, no. 2, pp. 14052-14056, 2003.

[42] L. Lens, S. V. Dongen, K. Norris, M. Githiru, and E. Matthysen, "Avian persistence in fragmented rainforest," Science, vol. 298, no. 5596, pp. 1236-1238, 2002.

[43] S. Harrison and E. Bruna, "Habitat fragmentation and largescale conservation: what do we know for sure?" Ecography, vol. 22, no. 3, pp. 225-232, 1999.
[44] C. Martínez-Garza and H. F. Howe, "Restoring tropical diversity: beating the time tax on species loss," Journal of Applied Ecology, vol. 40, no. 3, pp. 423-429, 2003.

[45] R. Levins, "Some demographic and genetic consequences of environmental heterogeneity for biological control," Bulletin of Entomological Society of America, vol. 15, pp. 237-240, 1969.

[46] I. Hanski and M. Gilpin, "Metapopulation dynamics: brief history and conceptual domain," Biological Journal of the Linnean Society, vol. 42, no. 1-2, pp. 3-16, 1991.

[47] I. Hanski, "Single-species metapopulation dynamics: concepts, models and observations," Biological Journal of the Linnean Society, vol. 42, no. 1-2, pp. 17-38, 1991.

[48] B. M. Stith, J. W. Fitzpatrick, G. E. Woolfenden, and B. Pranty, "Classification and conservation of metpopulations: a case study of the Florida scrub jay," in Metapopulations in Wildlife Conservation, D. R. McCullough, Ed., pp. 187-216, Island Press, Washington, DC, USA, 1996.

[49] J. Vandermeer and D. Goldberg, Population Ecology: First Principles, Princeton University Press, Princeton, NJ, USA, 2003.

[50] B. R. Noon and K. S. McKelvey, "A common framework for conservation planning: linking individual and metapopulation models," in Metapopulations in Wildlife Conservation, D. R. McCullough, Ed., pp. 139-166, Island Press, Washington, DC, USA, 1996.

[51] R. J. Gutierrez and S. Harrison, "Applying metapopulation theory to spotted owl management: a history and critique," in Metapopulations in Wildlife Conservation, D. R. McCullough, Ed., pp. 167-186, Island Press, Washington, DC, USA, 1996.

[52] S. Harrison, "Local extinction in a metapopulation context: an empirical evaluation," Biological Journal of the Linnean Society, vol. 42, no. 1-2, pp. 73-88, 1991.

[53] W. Heisenberg, Physical Principles of the Quantum Theory, General Publishing Limited, North York, ON, Canda, Dover edition, 1930.

[54] F. W. Preston, "The canonical distribution of commonness and rarity," Ecology, vol. 43, no. 2, pp. 185-215, 1962.

[55] N. C. A. Pitman, J. W. Terborgh, M. R. Silman, et al., "A comparison of tree species diversity in two upper Amazonian forests," Ecology, vol. 83, no. 11, pp. 3210-3224, 2002.

[56] G. G. Maina and H. F. Howe, "Inherent rarity in community restoration," Conservation Biology, vol. 14, no. 5, pp. 13351340, 2000.

[57] S. B. Ale and J. S. Brown, "Prey behavior leads to predator: a case study of the Himalayan tahr and the snow leopard in Sagarmatha (Mt. Everest) National Park, Nepal," Israel Journal of Ecology and Evolution. In press.

[58] S. L. Pimm, The Balance of Nature? University of Chicago Press, Chicago, Ill, USA, 1991.

[59] J. A. Wiens, "Spatial scaling in ecology," Functional Ecology, vol. 3, no. 4, pp. 385-397, 1989.

[60] D. O. Conover, "Fisheries: nets versus nature," Nature, vol. 450, no. 7167, pp. 179-180, 2007.

[61] K. T. Frank, B. Petrie, J. S. Choi, and W. C. Leggett, "Ecology: trophic cascades in a formerly cod-dominated ecosystem," Science, vol. 308, no. 5728, pp. 1621-1623, 2005.

[62] J. H. Lawton, "Are there general laws in ecology?" Oikos, vol. 84, no. 2, pp. 177-192, 1999.

[63] T. J. Quinn and R. B. Deriso, Quantitative Fish Dynamics, Oxford University Press, New York, NY, USA, 1999.

[64] N. Jonzén, P. Lundberg, E. Ranta, and V. Kaitala, "The irreducible uncertainty of the demography-environment interaction in ecology," Proceedings of the Royal Society B, vol. 269, no. 1488 , pp. 221-225, 2002. 
[65] J. Hjort, "Fluctuations in the great fisheries of northern Europe reviewed in the light of biological research," Rapports et Procès-Verbaux des Réunions du Conseil Permanent International pour l'Exploration de la Mer, vol. 20, pp. 1-228, 1914.

[66] R. Levins, "The strategy of model building in population ecology," American Scientist, vol. 54, pp. 421-431, 1966.

[67] F. Keyl and M. Wolff, "Environmental variability and fisheries: what can models do?" Reviews in Fish Biology and Fisheries, vol. 18, no. 3, pp. 273-299, 2008.

[68] C. Mullon, P. Fréon, and P. Cury, "The dynamics of collapse in world fisheries," Fish and Fisheries, vol. 6, no. 2, pp. 111-120, 2005.

[69] G. Caughley, "Directions in conservation biology," Journal of Animal Ecology, vol. 63, no. 2, pp. 215-244, 1994.

[70] S. P. Hubbell and R. B. Foster, "Diversity of canopy trees in a neotropical forest and implications for the conservation of tropical trees," in Chadwick Tropical Rain Forest: Ecology and Management, S. J. Sutton, T. C. Whitmore, and A. C. Chadwick, Eds., pp. 25-41, Blackwell Scientific Publications, Oxford, UK, 1983.

[71] W. F. Laurance, H. E. M. Nascimento, S. G. Laurance, et al., "Rapid decay of tree-community composition in Amazonian forest fragments," Proceedings of the National Academy of Sciences of the United States of America, vol. 103, no. 50, pp. 19010-19014, 2006.

[72] S. R. Carpenter, "Ecological futures: building an ecology of the long now," Ecology, vol. 83, no. 8, pp. 2069-2083, 2002.

[73] J. S. Brashares, P. Arcese, M. K. Sam, P. B. Coppolillo, A. R. E. Sinclair, and A. Balmford, "Bushmeat hunting, wildlife declines, and fish supply in West Africa," Science, vol. 306, no. 5699, pp. 1180-1183, 2004.

[74] J. S. Brashares, P. Arcese, and M. K. Sam, "Human demography and reserve size predict wildlife extinction in West Africa," Proceedings of the Royal Society B, vol. 268, no. 1484, pp. 24732478, 2001. 

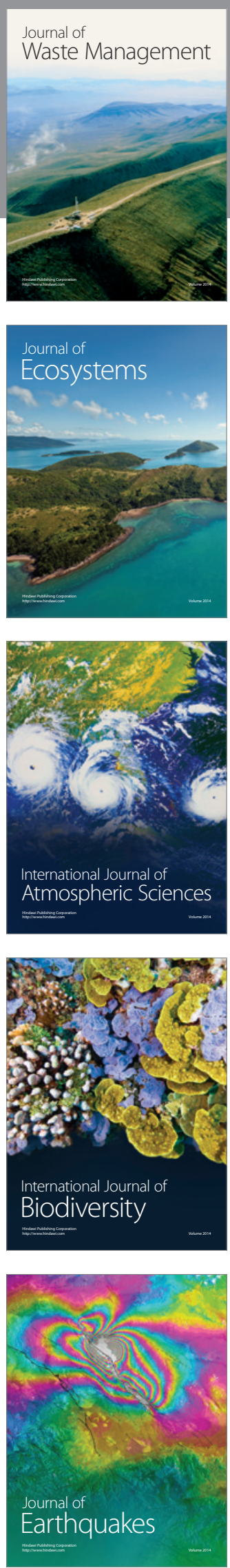
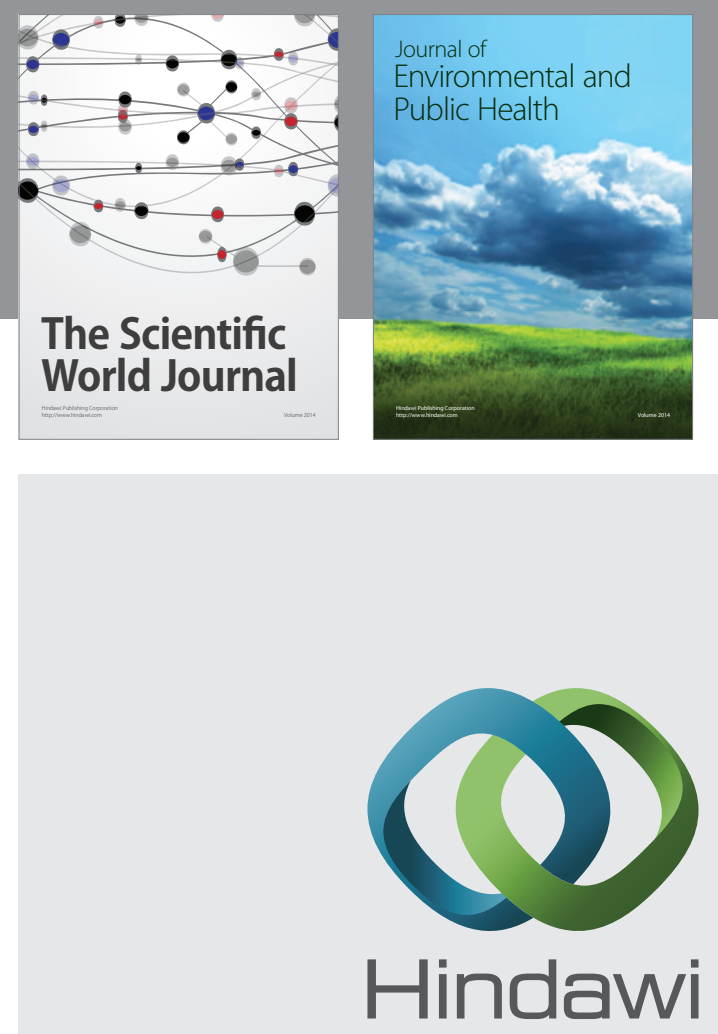

Submit your manuscripts at

http://www.hindawi.com
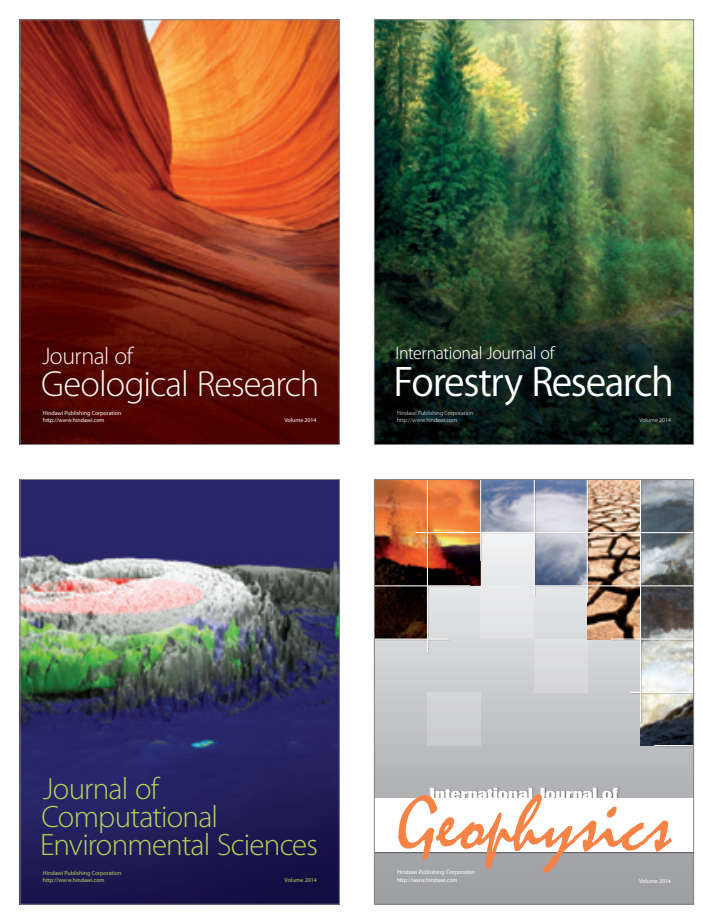
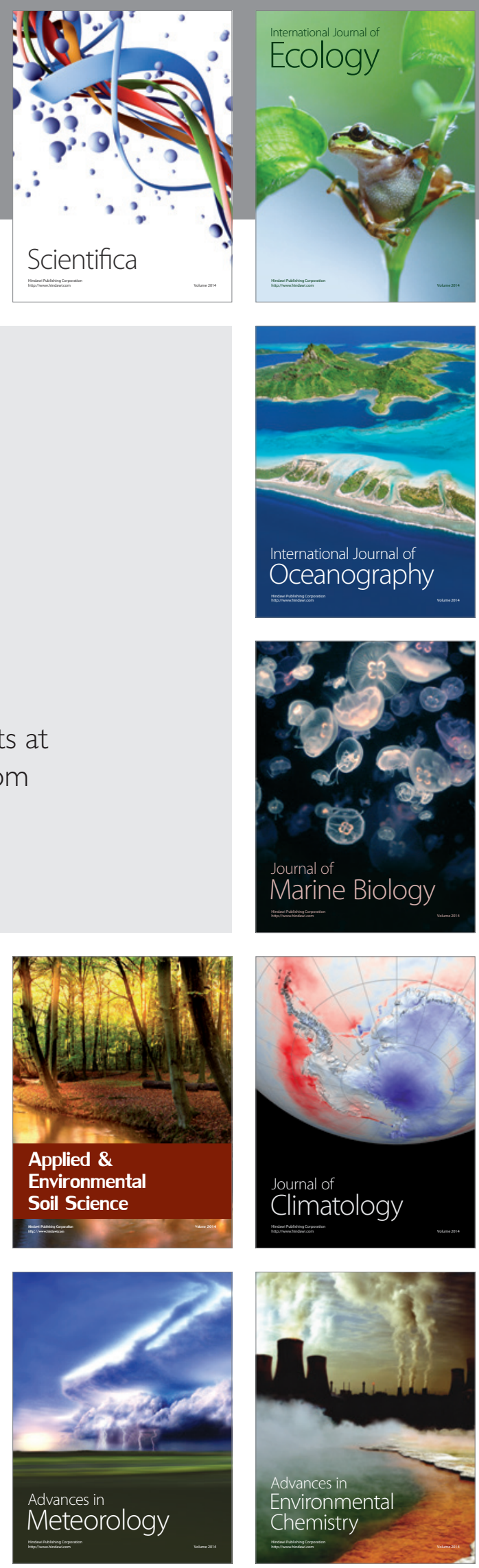